\title{
One month experience with anaesthesiology department of Hospital Universiti Sains Malaysia
}

\section{Hau Jett Lin}

Medical Student, School of Medical Sciences, Universiti Sains Malaysia, Malaysia.

\section{Context}

Anaesthesiology was not popular and is still relatively less popular compared to other specialties in Medicine [1]. This is mainly due to the misperception of the world towards anaesthesiology [1].

\section{Reason for the idea}

An operation which I underwent 3 years back first seeded my interest towards anaesthesiology. Since the Anaesthesiology and Intensive Care posting in Year 5 is only 2 weeks, I decided to have an attachment with the Anaesthesiology Department during my holidays after my Year 3 to explore more about anaesthesiology and intensive care as well as roles of anaesthetists. I also wished to obtain some experience on practical procedures before enrolling in Year 4.

\section{Methods}

The attachment was done for 4 weeks under the supervision of Dr Fadzlina, a master student in Anaesthesiology. I spent my first 2.5 weeks in Operation Theatre (OT) followed by 1.5 weeks in Intensive Care Unit (ICU). I joined the Continuous Medical Education sessions every Monday to Wednesday morning with the master students. During my days in OT, I attached to different anaesthetists in various Operation Rooms (ORs). I think this is indeed a good way of learning that you learn from people with different strengths. Moreover, I completed the Anaesthesiology and Intensive Care log book which is designed for the Year 5 students.

\section{Evaluation}

My most memorable experience throughout my one month Anaesthesia attachment was a case of patient having pulseless electrical activity on operation table. The ability of the anaesthetist to anticipate the complications, make necessary arrangements and react instantaneously during the incident indeed amazed me. I now recognize more about the importance of medical knowledge I learnt. "What else?" I found this a way to trigger more brain work; a way to recall and apply what we have learnt. I appreciate that not only I had the chance to learn about anaesthesiology and intensive care but I was exposed to about 50 different types of surgeries or procedures across different specialties during my 10 days in OT. Meanwhile, I think Anaesthesia attachment will also be a good exposure for students who like Surgery. Besides, I acknowledge more about the significance of a healthy inner me. I realized that it is not easy yet of utmost important, for a doctor particularly, to be tough yet soft in the heart at the same time. Tough, to endure hardships; soft in dealing with life. This attachment was indeed an eye opener. I am glad that I did this, for I would not have learnt so much if I did not.

\section{Reference}

1. Malaysian Society of Anaesthesiologists. From "Anaesthetist" to "Anaesthesiology and Critical Care"- The Evolution and Revolution in Teaching/Training. N.p. n.d. Web. 6 July 2012.

(c) Medical Education Department, School of Medical Sciences, Universiti Sains Malaysia. All rights reserved.

CORRESPONDING AUTHOR: Hau Jett Lin, Medical Students, School of Medical Sciences, Universiti Sains Malaysia, Malaysia. Email: jettlinhau@ hotmail.com 